\title{
Early Intervention Services, Importance and Availability Extent from Workers Point of View, Who Serves in the Intellectual Disability Centers in Ma'an, Jordan
}

\author{
Moneera Meheel Almsbhieen ${ }^{1}$ \\ ${ }^{1}$ Special Education Department, College of Education Sciences, Al-Hussein Bin Talal University, Ma'an, Jordan \\ Correspondence: Moneera Meheel Almsbhieen, Education Department, College of Education Sciences, \\ Al-Hussein Bin Talal University, Ma’an, Jordan. E-mail: meel@hotmail.com
}

Received: July 5, 2016

doi:10.5539/ies.v9n10p216
Accepted: August 18, $2016 \quad$ Online Published: September 28, 2016

URL: http://dx.doi.org/10.5539/ies.v9n10p216

\begin{abstract}
This study aims to highlight the importance of early intervention as to intellectual disabled children, level of its availability through the point of view generated from workers in Intellectual disability centers at Ma'an-Jordan. Moreover, we shall discuss herein the differences that carry statistical significance in early intervention services offered for intellectual disabled children that may be attributed to variables of gender, experience, qualification, specialty and center location.

The study sample has been formed from all workers at centers derived from the Ministry of Social development that offers its services to the intellectual disabled children, totaled at 44 (13males and 31 females).

In order to achieve the study aim, the researcher developed the study tool represented by a questionnaire consisting of two scopes; Importance of early intervention and its availability level, of 37 items. After confirming the tool stability and accuracy it has been applied on the study sample, then data was collected. We employed statistical methods; Person correlation coefficients, SMAs, Standard deviations and analyzing the multiple contrast.

The outcomes refer that the early intervention services importance is extremely high, and its availability is also at good level in the intellectual disability centers at Ma'an city. There were not differences of statistical significance at 0.5 level as to early intervention services importance offered for intellectual disabled children which are attributed to variables; gender, experience, qualification, specialty and center location. On the other hand, it was noticed the absence of differences of statistical significance at the level of early intervention services offered for intellectual disabled children that may be attributed to variables; gender, experience, qualification and specialty. While we noticed that there are differences of statistical significance as to the location variable. On the light of the generated outcomes we presented herein guiding and educational instructions in that regard.
\end{abstract}

Keywords: early intervention services, intellectual disability, workers point

\section{Introduction}

Special education field witnessed great attention especially in the 19th Century as a result of development of disability concept and inclusion thereof (Yeyha, 2006). The disability occupied the concern of all individuals and firms; private and Public sector, represented by laws and bylaws enactment that care of disability rights; i.e. disability rights law No. 31 of 2007 which guaranteed the disability rights in all scopes including early intervention services as referred to in article No. 4 in terms of health and education, whereas he emphasized on their right in inspection and early intervention as well as decreasing the disabilities to the minimum level, and offering health services in the closest locate to their local communities (Al Roosan, 2013). Many researchers and scholars in the private education field conducted studies and researches focusing on disabled scope. Hundreds of societies and institutions were established that care of disabled persons and offer services thereto (Al Zraiqat, 2009).

Out of the important subjects that received great attention is what is called early intervention including group of various services; i.e. Medical, social, educational and psychological services offered to children under six years old and suffering disabilities or congenital disability (Al Zraiqat, 2009). The foregoing includes skills 
development; such as academic skills and various knowledge skills and in the same time invest the remaining children abilities. Furthermore, it works to facilitate future learning processes and support the disabled children. Studies and researches refer to the fact that early intervention is more effective once applying thereof intensively and in early stages and could be fruitful once parents take part in such intervention, early intervention could be offered inside the house or center or through consultations offered to parents in the hospital (Rosenberg et al., 2008).

Disabilities that require early intervention are various types including, but not limited to, Intellectual disabilities. This is represents the mental function performance less than medium, which lead to decrease the adaptive behavior trends. Such types occur at the growth stages (Al Rosan, 2010).

Early intervention providers shall acquire many skills such as improving their social and linguistic skills, assessment and diagnosis, building and developing early intervention services and programs (Al-Khatib \& Al-Hadeedy, 2016). Early intervention was used in all the disabilities types; i.e. Autism (Landa et al., 2010) behaviors disorders (Osofsky \& Lieberman 2011; Armstrong et al., 2014), Audio disabilities (Al-Wohaib, 2013), and other disabilities.

Governmental institutions and centers worked to spread the early intervention services offered for all disabilities types by various specialized personnel in Pediatric Medicine, Neurology, natural treatment, Psychology, education and else. Such personnel have the ability to bring early intervention into success through their experience and knowledge gained in Diagnosis and treatment issues. The foregoing centers contribute in offering early intervention services to the Intellectual disabled children taking into consideration all the surrounding factors as to the disabled child and his family (Al-Khateeb \& Al-Hadidi, 2016).

Until the early intervention achieve its aims and objective, it basically depends on direct in charge personnel (employees and specialists) to provide such services or assessors thereof of both genders of various specialties and expertise or offices (Al-Khatib \& Al-Hadeedy, 2016). This role could be witnessed through comprehensive assessment as to their satisfaction as to the availability and importance of early intervention services. This, for sure, shall be reflected on the child and his performance in terms of receiving such services. In the same time it has big benefits especially what relating to future educational efforts (Abaid, 2012; Nuaimi, 2008). The foregoing shall work to provide decision makers with justifications on early intervention services efficiency, financial expenditures to establish such centers, also shall supply information that may develop and improve the services offered for children and their familes. Studies prepared by (Gholam \& Qadi, 2015; Naqbi, 2014; Sherbini \& Sayyed, 2013; Merza, 2013; Waheeb 2013; Qarni, 20007; Armstrong et al., 2014) all the foregoing referred to such improvements and developments

By virtue of the foregoing, the researcher tried herein to survey early intervention services in Ma'an city in terms of its importance and availability from the point of view of workers in the centers that offer services to children of intellectual disabilities.

\subsection{Study's Problem and Raised Questions}

Developing countries suffer from a high rate of disabilities, especially in the pre-school stage. Their number continues to increase, given poverty, diseases, drugs, accidents and wares which such countries are suffering, that such countries are suffering (Al-Zeriqat, 2009). Common sources tackling disability issues talk about $10 \%$ of children at pre-school age are suffering from disability or their status is not reassuring (Al-Khatib \& Al-Hadeedy, 2016).

The Intellectual disabilities are considered the most prevalent in worldwide countries, especially in Arab countries. In Jordan mental retardation is rated about 2-3\% (Al-Roussan, 2010.32), out of the Population in Jordan which is $(9,531,712)$, we came to a conclusion that intellectual disabilities cases are ranged from 190-285 thousand inhabitant. In Ma'an city the total inhabitants therein is 127989 and thus the intellectual disabled persons are ranged from 2600-3800, based on 2016 statistics (Department of Statistics, 2016).

Due of the high rate of intellectual disability, compared with other disabilities in the Jordanian society, the researcher decided to study of the reality of early intervention services for the intellectual disabled, as offering care thereto becomes human and legal right, represented by making care and direction opportunities available for each individual, especially as they are in dire need of this to exploit their abilities to the fullest extent possible (Hebbeler et al., 2007).

Through communicating with the special education centers in the Governorate of Ma'an and supervising students in private education centers while practicing site training, in addition to communicating with the intellectual disabled families, the researcher noticed some shortage as to early intervention services offered by 
such centers. The researcher tried herein to identify the availability of early intervention services by surveying the centers' personnel's point of views who she believes have the ability to discover the weak points in such services.

Therefore the following questions were set out seeking replies thereto:

1) What level of importance of early intervention services for children with intellectual disabilities from the perspective of workers in the Governorate of Ma'an?

2) What level of availability of early intervention services for children with intellectual disabilities from the perspective of workers in the Governorate of?

3) Are there significant differences at the level of $(\alpha \leq .05)$ in the level of importance of early intervention services for children with intellectual disabilities attributable to the variables (Gender-years of experience-Qualification-Specialization-and Place)?

4) Are there any statistically significant differences at the level of $(\alpha \leq .05)$ in the level of availability of early intervention services for children with intellectual disabilities attributable to the variables (Gender-years of experience - Qualification - Specialization and Place)?

\subsection{Objectives of the Study}

This study aimed to identify the importance and availability of early intervention services offered for children with intellectual disabilities, from the personnel point of views, and whether there are differences of significance in such point of views that is attributable to variables; gender, experience, qualification, specialty and location.

\subsection{The Importance of Study}

The current study derives its importance from two scopes; i.e.

Theoretical importance: The importance of the current study is the lack of similar studies in the Jordanian society in general, especially in southern Jordan region, where the researcher did not find any previous study on the subject of the study-the subject of interest-, so the importance of this study lies in the new addition to scientific research with respect to early intervention for the intellectual disabled in terms of its importance, and the availability of services to the intellectual disabled centers in governorate of Ma'an.

Applied importance: The importance of this study by revealing the results, which hopefully will reveal deficiencies that may appear in any aspect of early intervention, whether in terms of awareness of its importance or in the application of its services, to put those results and provide as a evidence before the officials and decision-makers in order to avoid errors existing and work on the development of these services.

The study also seeks to identify early intervention importance level as to intellectual disabled children who benefit of educational institutions from the point of view of teachers and supervisors in such centers. Also to identify such services stand and possibility to developing thereof in the future. The foregoing shall work to invest suitable time in the disabled child and generate benefit to him and his family, present recommendations to focus on weakness points which prevent from achieving early intervention aims.

\subsection{Previous Studies}

Ghulam and Kady (2015), study aimed at detecting the level of services provided by special educational institutions in Tripoli-Libya over the Mediterranean from the perspective of workers in those centers and the relative ranking of those services, the study sample consisted of (150) of the staff, administrators and social workers and psychologists who work in those centers, a questionnaire was applied to the sample and the results showed that the level of services provided by special education institutions in the city of Tripoli-Libya above average.

Al-Naqbi (2014), study aimed to justify the role of Zayed Higher Organization for Humanitarian Care and Special Needs in Abu Dhabi Emirate with regard to the early intervention, and study sample consisted of (175) In loco parentis and (140) children who included all types of disabilities who are under the age of (5) years, whether they are citizens or residents of the Emirate of Abu Dhabi, and some of the programs that presented by this institution: categorical programs as a developmental menu program (Portage), support services, programs supporting educationally, socially and programs of family, and the results showed that the proportion of the presence of parents in early intervention Unit for educational programs amounted to $82 \%$, and the percentage of their participation in the unity of early intervention amounted to $95 \%$, and the proportion of households participate ranged in projects and outreach programs provided to them between 80-100, while the age groups-that children were involved in early intervention programs-between the old rate rose to (3-4) years, the proportion of 
Intellectual disability as well as increased more than other disabilities in early intervention services.

The purpose of the study carried out by El-Al-Sherbini and Sayed (2013), to identify the most important challenges facing the application of programs in the Omani society and the gyptian community, study sample consisted of (150) families, (75) families of Omani society and (75) a families of Egyptian society, And the study tool was semi-Accurate interviews as well as data collection form, and the results indicated that $51 \%$ of parents of intellectual disabled children in the Omani society do not realize that early intervention, as well as (50.25) of the sons of Egyptian society did not enroll their children with Intellectual disabilities in early intervention programs.

The aim of the study also conducted by Mirza (2013), to build a national system for the childhood and early intervention services in of whole Gulf states, as well as the importance of early intervention and national feasibility through the provision of those services and analytical discussion of the reality of services in the Kingdom of Saudi Arabia as a model through refute strengths and weaknesses, the researcher has reviewed many of the weaknesses that limit the effectiveness of these services such as the lack of clear national policies with regard to early intervention as well as the limited scientific research to keep up with global research and the difficulty of determining the size of disability in early childhood under six years.

Al-Wohaib (2013), study aim to recognize the importance of early intervention services for children Deaf and Hard of Hearing from the viewpoint of specialists, the availability of those services and also aimed to know these trends that affected on the variables like gender, educational qualification, specialization, years of experience and place of service, the study sample consisted of all employees in hearing disability centers in the city of Riyadh's that has a number (111) (25 males and 86 females), a questionnaire were applied on a sample study and the results revealed the agreement of members sample the importance of (early intervention services for deaf children) As well as it's availability,and there were no significant differences related to the study variables, whether in the importance of early intervention or provide these services except for the presence of statistically significant differences in the availability of services, regarding with two variables : years of service for the benefit of people with the service for more than five years, and place of service for the benefit of hospitals.

Abaid (2012) evaluates the efficiency level of governmental and private mental retarded centers at the capital governorate (Amman). The study sample included (9) mental retarded centers; two are governmental and (7) are private. Study instrument is consisted of various dimensions; the study showed that evaluation of governmental and private centers efficiency was at higher level, but the private centers compared with the governmental centers indicating to the existence of higher efficiency at eh centers compared with the governmental centers, indicating to the existence of higher efficiency at eh private centers compared with the governmental centers.

While Al-Naimi (2008), study was aimed at evaluating early intervention programs offered for the intellectual disabled in the United Arab Emirates from the teachers and mothers perspective, study sample consisted of 112 of them (71) mothers and (41) a teachers in six centers for early intervention in year (2008/2007), A questionnaire was applied on a sample study and the most important of study results and no statistically significant differences in the evaluation of early intervention programs provided for the disabled intellectually from the standpoint of mothers attributed to the level of Intellectual disability in favor with mild disabilities, as well as the lack of statistically significant differences in the evaluation of early intervention programs offered to the intellectual disabled from the perspective of mothers Attributed to the gender of the disabled, the researcher recommended that the development of early intervention programs provided for the intellectual disabled in the United Arab Emirates.

The Al-Qarni (2007), study aimed to know the effectiveness of early intervention programs provided for the hearing impaired at government and private institutions in Jeddah from the perspective of workers, the study sample consisted of (86) factors working in these centers, A questionnaire were applied by the researcher on the respondents where has shown results that the educational side aspect more effective than family side, the medical side, and it was more effective males than females, and there is an effect for the scientific qualification on the graduate, but the experience variable had not any effect.

The aim of the study that presented by Abid (2005), was to identifying the role of the local community in providing services to the Intellectual disabled, to identify the most important obstacles that hinder the provision of services and to identify the reasons that hinder adaptation process for them, in Gaza province,the study sample consisted of (45 mothers from mothers of children with Intellectual disabilities and (15) staff who work in the institutions working in the field of Intellectual disability have used the interview as a tool to study the views of all groups agreed that the institutions have not been able to meet children with intellectual disabilities needs and workers agreed that the educational level of workers is average, have no academic qualifications, a lack of a 
dedicated team with a scientific, professional efficiency, there is a big gap between the services provided to the disabled, the services they need and lack of plans for the centers or a curriculum for practical training.

\section{Method}

This research adopts descriptive analytical approach, which was selected due to its applicability hereto in terms of methodology and objectives.

\subsection{Variables of the Study}

A-Independent :The gender with two levels (1-male, 2-female), specialization has two levels also (1- private Education, 2-other), scientific qualification has five levels (1- secondary 2-diploma two years, 3- Bachelor 4-Master 5-Doctorate) years of experience have three levels (1-less than 5 years, 2 -from (5-10)and 3- is more than 10 years), And the location of the center has two levels (1-city, 2-Village).

B-dependent: point of view from workers in Intellectual disability centers at Ma'an - Jordan.

\subsection{Study Community and Sample}

The study community represents all personnel employed at centers derived from the Ministry of social development that offering its services to the intellectual disabled persons. There are 8 operating centers in Ma'an province, employing 44 personnel; (13) males and (31) females, all were selected within the research targeted sample which represents the research community as well.

Table 1 hereinafter, presents respective centers' personnel, derived from the Ministry of social development, that offer its services to the intellectual disabled persons in serial order as to workers number, gender, qualifications, specialty, experience and work premises:

Table 1. Distribution of the study population according to gender, years of experience, specialization, qualification, \& place work $(\mathrm{N}=44)$

\begin{tabular}{lcc}
\hline 13 & Males & Gender \\
31 & Females & \\
\hline 16 & 5 & \\
22 & $5-10$ & Years of Experience \\
6 & More than 10 & \\
\hline 13 & High School & \\
13 & Diploma two years & \\
17 & Bachelor & Specialization \\
- & Master & \\
1 & Doctorate & \\
\hline 20 & Special Education & Qualification \\
24 & Other & \\
\hline 31 & City & Place work \\
13 & Village & \\
\hline
\end{tabular}

\subsection{The Study Procedures}

The researcher conducted thorough review of theoretical literature and a studies of concern as to this research subject, the study tool has been developed. Once such tool accuracy and stability is confirmed, the researcher paid a visit to social development directorate in Ma'an city and explained the aim of this study. In her visit she could allocate the centers that offer service for intellectual disabled persons in $\mathrm{Ma}$ 'an. The directorate called the respective centers and directed personnel in charge to facilitate the researcher mission and cooperate with her. Further the researcher paid a visit to these centers whereas the questionnaire (study tool) have been filled in due manner. 


\subsection{Statistical Treatment Methods}

We used herein Person Correlation coefficient, SMAs, standard deviations and analyzing the dual variation in order to verify early intervention importance and services availability levels for disabled children with intellectual disabilities, derived from the persons in charge at Ma'an province, and to verify the variables' impact; i.e. (Gender, qualification, specialty, experience and location.

\subsection{The Study Tool}

The researcher worked to develop the questionnaire addressed to the personnel working in the Ministry of Social Development who offers its services to intellectual disabled persons in Ma'an province. The researcher leaned on theoretical literature and previous studies of concern as to early intervention, i.e. (Al-Wohaib. 2013; Al-Qarni, 2007; Al-Naimi, 2008; Mirza, 2013), The questionnaire consisted of two parts, the first part of the questionnaire stating the purpose of the study and the necessary instructions to respondents about how to answer questions, as well as personal information about them, which represents the study variables (gender, years of experience, qualification, and the place of the center), the first dimension refers to the importance of early intervention services for children with Intellectual disabilities that includes (22) items. the second dimension refers to the availability of services provided by private education centers from the viewpoint of specialists working in these centers includes (15) items, The scale used a five-point Likert format, and the responses to the statements were coded as follows: Strongly Disagree $=1$, Disagree $=2$, Not Sure $=3$, Agree $=4$, and Strongly Agree $=5$.

The early intervention questionnaire items include assessment and early diagnoses, home visits, early family guidance, family and centers personnel training, psychological, social, medical and Therapeutic services.

\subsection{Questionnaire Validity}

The original questionnaire has been presented to group of specialists in private education and early childhood, psychology, curriculums and styles. They were asked to comment of each paragraph in the questionnaire; drafting, its consistency as to the research subject. The selected arbitrators offered their comments and recommendations on the set out questionnaire. Such comments were taken into consideration by the researcher once re-drafting the questionnaire. Total initial items were 44 and after reviewing thereof it become 37 Items. We used also herein Staging Quintet instead of triple staging, and thus the tool acquired its final drafting image.

The researcher depended on arbitrators' truth to develop the questionnaire through reviewing many studies that handled same study subject supported by theoretical literature. Also the researcher met the personnel who work in such centers before developing the questionnaire and obtained their point of view on the most important services they deem necessary as to early intervention process, all were taken into consideration on developing the questionnaire.

\subsection{Questionnaire Reliability}

Questionnaire reliability has been confirmed by applying current study tool on initial sample consisting of 8 workers in special education centers at Ma'an province selected from outside the study sample, but they share the current study individuals in terms of academic, cultural, social and economic levels. Reliability coefficients have been extracted via dual internal consistency; Cronbackh Alpha and Retail midterm as presented in the hereinafter Table 2.

Table 2. Test-retest reliability

\begin{tabular}{lcc}
\hline Dimensions & $\begin{array}{c}\text { Cronbackh } \\
\text { Alpha }\end{array}$ & $\begin{array}{c}\text { Corrector Retail Midterm via Speerman } \\
\text { Brown equation? }\end{array}$ \\
\hline Early intervention services importance level & 0.90 & 0.91 \\
$\begin{array}{l}\text { Availability level of early intervention services } \\
\text { in the centers }\end{array}$ & 0.89 & 0.88 \\
Total & 0.90 & 0.89 \\
\hline
\end{tabular}

Truth coefficients and reliability are considered accepted for the current study purposes. 


\section{Result}

The first question: What is the early intervention services importance' level which is offered for intellectual disabled children from the point of view of workers and personnel of Intellectual disability centers at Ma'an province?

In reply to the above question, we calculated the SMAs and standard deviations of individuals' responses as to such sector. Generated outcomes are presented in Table 3 hereinafter.

Table 3. SMAs and standard deviations as at early intervention services importance sector offered for intellectual disabled children

\begin{tabular}{|c|c|c|c|}
\hline Sequence & The paragraph & Mean & $\begin{array}{c}\text { Td. } \\
\text { Deviation }\end{array}$ \\
\hline 1 & $\begin{array}{l}\text { Diagnostic services, early identification of disabled children to contribute in } \\
\text { confirming the presence of disability or denial }\end{array}$ & 4.5000 & .50578 \\
\hline 2 & $\begin{array}{l}\text { Diagnostic services contribute to the early identification and to determine } \\
\text { the causes of disability in children with intellectual disabilities }\end{array}$ & 4.8182 & .39015 \\
\hline 3 & $\begin{array}{l}\text { Diagnostic services, early identification of children with intellectual } \\
\text { disabilities to contribute in determining the nature of the treatments they } \\
\text { need in a timely manner. }\end{array}$ & 4.3864 & .65471 \\
\hline 4 & $\begin{array}{l}\text { Early diagnosis and identification services contribute to the optimal } \\
\text { investment to stimulate the abilities of disabled children in the early years } \\
\text { of age }\end{array}$ & 4.6591 & .56828 \\
\hline 5 & $\begin{array}{l}\text { Diagnostic services, early identification of disabled children to contribute in } \\
\text { overcoming the problems and reduce the aggravation in the future }\end{array}$ & 4.6591 & .56828 \\
\hline 6 & $\begin{array}{l}\text { Service home visits for disabled children contribute to the early years of } \\
\text { age in a child's access to appropriate service in the natural environment (the } \\
\text { family) }\end{array}$ & 4.7500 & .53374 \\
\hline 7 & $\begin{array}{l}\text { Service home visits for disabled children contribute to the family } \\
\text { involvement and activate its role }\end{array}$ & 4.7500 & .43802 \\
\hline 8 & $\begin{array}{l}\text { Early family counseling services contribute to the development of } \\
\text { awareness of the problems of the disabled child }\end{array}$ & 4.4773 & .50526 \\
\hline 9 & $\begin{array}{l}\text { Early family counseling services contribute to the achievement of } \\
\text { cooperation with specialists }\end{array}$ & 4.6591 & .56828 \\
\hline 10 & $\begin{array}{l}\text { Family Counseling Services contribute early to participate in the evaluation } \\
\text { process }\end{array}$ & 4.2955 & .66750 \\
\hline 11 & $\begin{array}{l}\text { Early family counseling services contribute to the development of } \\
\text { awareness of the causes to prevent a marriage of relatives and drugs ... etc. } \\
\text { to reduce disability in the community }\end{array}$ & 4.7045 & .59375 \\
\hline 12 & $\begin{array}{l}\text { Early family training in activating the role of the family contribute to the } \\
\text { service and receive a disabled child the necessary services in a timely } \\
\text { manner in the house constantly }\end{array}$ & 4.7045 & .63170 \\
\hline 13 & $\begin{array}{l}\text { Early family and workers in service training centers contribute to the } \\
\text { development of dealing with disabled children skills better }\end{array}$ & 4.7500 & .61474 \\
\hline 14 & $\begin{array}{l}\text { early intervention in educating family options to communicate with their } \\
\text { child with a disability services contribute }\end{array}$ & 4.3864 & .65471 \\
\hline 15 & $\begin{array}{l}\text { early intervention services contribute to determining the appropriate } \\
\text { educational center of the child's disability }\end{array}$ & 4.3182 & .63878 \\
\hline 16 & $\begin{array}{l}\text { early intervention in the rehabilitation specialists programs contribute } \\
\text { through workshops }\end{array}$ & 4.1591 & .68005 \\
\hline
\end{tabular}


17 early intervention to alleviate the psychological pressure that the child and his family faced because of disability services contribute

4.2500

.68624

$$
\text { early intervention services contribute to the integration of the child in }
$$
society

4.1818

.78571

early intervention in the provision of assistive devices and auxiliary equipment for people with Intellectual disabilities services contribute

4.2500

.71933

early intervention in the developmental aspects of child development services contribute

4.3182

.73998

Early medical services contribute to the follow-up of children with Intellectual disabilities and to provide appropriate medical treatment in the early stages of Intellectual disability

Services that submit physiotherapist career processor in mitigating the impact of Intellectual disability contribute

Evident from the Table 3 that the importance of early intervention in general level got to evaluate (Strongly agree), so by looking at the total of the arithmetic average that amounting (4.49277), given the arithmetic mean of the responses of respondents about the level the importance of early intervention services for children with Intellectual disabilities It ranged from (4.8182 and 4.2955) and this falls within the assessment of (strongly agree).

The Second question: What is the level of availability of early intervention services for children with Intellectual disabilities from the perspective of workers in Intellectual disability centers in the Governorate of Ma'an?

To answer this question, the arithmetic means and standard deviations of the responses of the individuals have been calculated on this axis, the results were as illustrated in Table 4 .

Table 4. SMAs and standard deviations as to early intervention services availability

\begin{tabular}{|c|c|c|c|}
\hline Sequence & The Paragraph & Mean & $\begin{array}{c}\text { Std. } \\
\text { Deviation }\end{array}$ \\
\hline 23 & $\begin{array}{l}\text { The center offers which I am working measuring instruments reliable and } \\
\text { valid for diagnosing Intellectual disability }\end{array}$ & 3.3182 & .50578 \\
\hline 24 & $\begin{array}{l}\text { The center offers where I work and developmental league mental health } \\
\text { disability detection services }\end{array}$ & 3.3864 & .39015 \\
\hline 25 & $\begin{array}{l}\text { The center offers which I work evaluation and diagnosis of Intellectual } \\
\text { disability within a multidisciplinary team }\end{array}$ & 3.4545 & .65471 \\
\hline 26 & $\begin{array}{l}\text { (The center which I working in) Is available professionals has the ability to } \\
\text { diagnose children with Intellectual disability }\end{array}$ & 2.7955 & .56828 \\
\hline 27 & $\begin{array}{l}\text { The center offers where I work early services commensurate with the } \\
\text { weaknesses in children with Intellectual disabilities }\end{array}$ & 3.6364 & .56828 \\
\hline 28 & The center offers services where I work early visits to homes & 4.1364 & .53374 \\
\hline 29 & $\begin{array}{l}\text { The center offers in which the working world, domestic programs such as } \\
\text { Albortj }\end{array}$ & 3.2955 & .43802 \\
\hline 30 & The center offers where I work early family counseling services & 3.3864 & .50526 \\
\hline 31 & $\begin{array}{l}\text { The center offers which I am working lectures to the families of the } \\
\text { Intellectually disabled }\end{array}$ & 4.0000 & .56828 \\
\hline 32 & $\begin{array}{l}\text { The center offers consulting services, which works by a multidisciplinary } \\
\text { team to the families of the disabled }\end{array}$ & 3.1591 & .66750 \\
\hline
\end{tabular}




\begin{tabular}{llll}
\hline 33 & $\begin{array}{l}\text { The center where I work Hold various training workshops for families of } \\
\text { disabled }\end{array}$ & 3.2955 & .59375 \\
34 & $\begin{array}{l}\text { The center where I work Hold different various training workshops for } \\
\text { employees at the center }\end{array}$ & 3.8409 & .63170 \\
35 & $\begin{array}{l}\text { The center where I work is available different activities and events for } \\
\text { families of the Intellectual disabled }\end{array}$ & 3.6364 & .61474 \\
36 & $\begin{array}{l}\text { The center where I work and trips hold a position to the Intellectual } \\
\text { disabled competitions }\end{array}$ & 3.5909 & .65471 \\
37 & $\begin{array}{l}\text { The center offers in which the working plans and programs for the } \\
\text { integration of the Intellectual disabled }\end{array}$ & 4.1591 & .63878 \\
Total & & 3.5393 & .68005
\end{tabular}

Evident from the Table 4 to assess the respondents to the level of availability of early intervention services for children with Intellectual disabilities in general got to evaluate (agree), and given the arithmetic mean of the responses of respondents about the level the importance of early intervention services for children with Intellectual disabilities, ranged from (4.1591 and 2.7955) and it signals a good proportion of the agreement between the respondents responses on providing early intervention services for children with Intellectual disabilities in those centers.

The Third question: Is there a statistically significant difference at level of $(\alpha \leq .05)$ in the level of importance of early intervention services for children with Intellectual disabilities attributable to the variables of (Gender-Years of Experience-Qualification-Specialization-and Place)? To answer this question, the arithmetic means and standard deviations of the responses of the study sample have been calculated as it appears in the Table 5 .

Table 5. SMAs and standard deviations in terms of study sample responses on early intervention services importance level that are attributed to variables of (Gender-Years of Experience-Qualifications-Specializationand Place of Center)

\begin{tabular}{llccc}
\hline The source & & No. & Mean & Std. Deviation \\
\hline \multirow{3}{*}{ Gender } & Male & 13 & 91.1888 & 4.05514 \\
& Female & 31 & 89.2962 & 10.82724 \\
& Total & 44 & 89.8554 & 9.33487 \\
\hline \multirow{5}{*}{ Experience Year } & less than 5 & 16 & 88.3523 & 12.27427 \\
& $5-10$ & 22 & 92.1074 & 5.29631 \\
& more than 10 & 6 & 85.6061 & 11.33147 \\
& Total & 44 & 89.8554 & 9.33487 \\
\hline \multirow{5}{*}{ Qualification } & school & 13 & 87.4126 & 7.09873 \\
& Diploma & 13 & 90.9091 & 8.93811 \\
& Bachelor & 17 & 90.3209 & 11.13841 \\
& Doctorate & 1 & $1.0000 \mathrm{E} 2$ & \\
& Total & 44 & 89.8554 & 9.33487 \\
\hline \multirow{5}{*}{ Special } & Special Education & 20 & 90.2273 & 10.53536 \\
& Others & 24 & 89.5455 & 8.42630 \\
& Total & 44 & 89.8554 & 9.33487 \\
\hline \multirow{5}{*}{ Place } & City & 31 & 90.4399 & 4.28895 \\
& Village & 13 & 88.4615 & 16.225 \\
& Total & 44 & 89.8554 & 9.33487 \\
\hline
\end{tabular}


Notes from the table above, existence of clear We notice from the above differences between the arithmetic averages of the performance of members of the study on the scale of the importance of early intervention services, and to reveal whether there were statistically significant differences between the workers responses in the Intellectual disability centers of $\mathrm{Ma}$ 'an governorate around the axis of the importance of early intervention services for children with Intellectual disabilities attributable to the variables of (Gender-years of experience-Qualifications-Specialization-and Place of Center), has used multiple analysis of variance of the responses of the study sample as it appears in the Table 6.

Table 6. Multiple analyses of variance in terms of study sample responses of concern as to early intervention services importance which is attributed to variables (Gender-Years of Experience-Qualifications-Specializationand Place of Center)

\begin{tabular}{cccccc}
\hline Sig. & F & Mean Square & Df & $\begin{array}{c}\text { Type III Sum of } \\
\text { Squares }\end{array}$ & Source \\
\hline .367 & 1.132 & 96.253 & 8 & $770.022^{\mathrm{a}}$ & Corrected Model \\
.000 & 893.903 & 76032.615 & 1 & 76032.615 & Intercept \\
.807 & .060 & 5.127 & 1 & 5.127 & Gender \\
.092 & 2.556 & 217.427 & 2 & 434.855 & Experience Year \\
.147 & 1.902 & 161.789 & 3 & 485.366 & qualification \\
.187 & 1.815 & 154.370 & 1 & 154.370 & Special \\
.349 & .902 & 76.703 & 1 & 76.703 & Place \\
& & 85.057 & 35 & 2976.992 & Error \\
& & & 44 & 359002.479 & Total \\
& & & 43 & 3747.014 & Corrected Total \\
\hline
\end{tabular}

Table No. 6 does not present differences in responses received from workers and personnel enrolled in the Intellectual disability centers at Ma'an province and tackle early intervention services importance offered for intellectual disabled children that are attributed to variables; (Gender-Years of Experience-QualificationsSpecialization-and the place of center).

The Fourth Question: Are there any statistically significant differences at $(\alpha \leq .05)$ in the level of availability of early intervention services for children with Intellectual disabilities attributable to the variables of (GenderYears of Experience - Qualification - Specialization -and Place)?

In reply thereto: The arithmetic means and standard deviations of the responses of the study sample have been calculated as it appears in the Table 7. 
Table 7. SMAs and standard deviations of workers responses in I.D. centers at Ma'an province to availability of early intervention services sector, offered for I.D. children which are attributed to variables; (Gender-Years of Experience-Qualification-Specialization-and Place of Center)

\begin{tabular}{ccccc}
\hline The source & & No. & Mean & Std. Deviation \\
\hline \multirow{3}{*}{ Gender } & Male & 13 & 70.8718 & 12.74067 \\
& Female & 31 & 70.7527 & 14.89891 \\
& Total & 44 & 70.7879 & 14.14818 \\
Experience Year & less than 5 & 16 & 70.6667 & 14.80741 \\
& $5-10$ & 22 & 69.7576 & 15.00271 \\
& more than 10 & 6 & 74.8889 & 9.66705 \\
Qualification & Total & 44 & 70.7879 & 14.14818 \\
& school & 13 & 71.2821 & 4.16744 \\
& Diploma & 13 & 72.2051 & 18.32097 \\
& Bachelor & 17 & 67.7647 & 14.75154 \\
Special & Doctorate & 1 & 97.3333 & \\
& Total & 44 & 70.7879 & 14.14818 \\
& Special Education & 20 & 72.2667 & 14.51339 \\
& Others & 24 & 69.5556 & 14.02643 \\
& Total & 44 & 70.7879 & 14.14818 \\
& City & 31 & 74.7097 & 12.60915 \\
& Village & 13 & 61.4359 & 13.61330 \\
& Total & 44 & 70.7879 & 14.14818 \\
\hline
\end{tabular}

Notes from the table above, existence of clear differences between the arithmetic averages of the performance of members of the study on the scale of the availability of early intervention services, and to find out whether these differences are statistically significant, multiple analysis of variance has been used of the responses of the study sample as it appears in the Table 8 .

Table 8. Multiple analysis of variance of study sample responses on availability extent of early intervention services that are attributed to variables; gender, experience, qualifications, specialty and location

\begin{tabular}{cccccc}
\hline Sig. & F & Mean Square & df & $\begin{array}{c}\text { Type III Sum } \\
\text { of Squares }\end{array}$ & Source \\
\hline .035 & 2.401 & 381.212 & 8 & 3049.699 & Corrected Model \\
.000 & 349.689 & 55527.120 & 1 & 55527.120 & Intercept \\
.478 & .515 & 81.813 & 1 & 81.813 & Gender \\
.393 & .749 & 118.899 & 1 & 118.899 & Special \\
.130 & 2.016 & 320.067 & 3 & 960.200 & Qualification \\
.008 & 7.954 & 1263.094 & 1 & 1263.094 & Place \\
.211 & 1.629 & 258.748 & 2 & 517.496 & Experience Years \\
& & 158.790 & 35 & 5557.655 & Error \\
& & & 44 & 229088.000 & Total \\
& & & 43 & 8607.354 & Corrected Total \\
\hline
\end{tabular}


Evident from the Table 8 that there were no statistically significant differences at level of $(\alpha \leq .05)$ among workers responses in the Intellectually disability centers in governorate of Ma'an about the axis of the availability of early intervention services for children with Intellectual disabilities attributable to the variables of (Gender-years of experience-qualification-and specialization), while there is statistically significant differences at level of $(\alpha \leq .05)$ with respect to a place variable.

\section{Discussion}

In order to achieve this study objective; identifying the importance of early intervention services offered for intellectually disabled children and availability thereof, the researcher selected I. D. Centers in Ma'an province. The researcher academic background represented by her filled office as senior supervisor on the BA degree students; major private education, who apply field training in some of above mentioned centers. Therefore, the researcher started to oversight the theoretical side and related studies, and she worked to develop this study tool; reliability and accuracy thereof have been confirmed then the researcher applied such tool on the study sample consisted of 44 workers and personnel who are enrolled on these I.D centers. Further the researcher dealt with statistical data; presentation and analysis, then discussing the outcomes on the light of the study questionnaire, theoretical literature and previous studies. The generated outcomes represented by many determinants and focused on early intervention services in terms of importance and availability, and lastly it has been applied on centers that offer early intervention services to Intellectual disabled children in Ma'an province. The foregoing has been applied during the 2nd semester 2015/2016.

This study employed all workers and personnel (teachers and administrative personnel) who are enrolled in these centers. Within such determinants this study reached at the following outputs:

In reply to the first question, the responses of the study sample it is witnessed that early intervention services offered for I.D. children occupies great importance. This offers an interpretation that this sector is the first step to be adopted in terms of offering early intervention services as it is considered basic issue in early identification of the disability which shall facilitate therapeutic plan and apply thereof in efficient and easy mode.

With respect to the first question has been the results of the study sample responses shown the large importance for early intervention services for children with Intellectual disabilities, it can be explained by the importance of early intervention that is the basis for the discovery of a disability during the assessment, diagnosis and training to invest all the remaining capacities of the child and one amendment can be modified, and early intervention takes care of the parents by provide guidance and support myself for avoiding negative trends and psychological suffering that may be exposed as a result of disability, as well as entrench their correct patterns in education with the help of a team of specialists where shared by the parents and the child, and whenever were early, the results were effective, because of disability whenever delayed the delivery of services for intellectual disabled children where whenever aggravation of danger and it affected all other growth aspects (Al-Zeriqat, 2009), it have been told (an ounce of prevention is worth a pound of cure), so two of people do not differ on the importance of early intervention, as Meisels mentioned referred him to (Al-Khatib \& Al-Hadeedy, 2016) results reached by scientific studies have provided strong evidences of the importance of early intervention even that it does not need to ask questions about its relevance and effectiveness, and this result is consistent with the results of each of (Al-Naqbi, 2014; Al-Wohaib, 2013) studies regarding the importance of early intervention.

Regarding the second question, and when respondents responses analyzed, the results showed that these centers provide early intervention Services for children with Intellectual disabilities in those centers by good rate, this can be explained by the development that witnessed by the special education field in Jordan which represent by legislation laws like law the rights of persons with disabilities No. (31) of 2007, which focused on many of the rights of individuals with disabilities in many different areas such as health, vocational rehabilitation, (education in schools, universities), provide all the environmental facilities such as buildings, public utilities, the customs and tax exemptions, (public and political life, sports, culture, entertainment, and litigation (Al-Rousan, 2013), as the number of researchers and students in special education field were conducting studies and research in the field of disability, and founded hundreds of associations and institutions, which focused on the affairs of the disabled, and which provides various services for people with disabilities (Al-Zeriqat, 2009), so that Jordanian universities receive many of the sons of the Arab countries to study the special education specialization, as well as receiving the assessment and diagnosis centers of many of disability cases to be diagnosed in Jordan, as well as the special education institutions in Jordan hold a lot of training courses to improve job performance level for workers in those centers, whether they are employees or volunteers which relate with diagnosis, training and training construction programs, and there are in Jordan, many trainers with experience and competence which receiving those centers to training within them, and that's what makes a good service in those centers. 
The results of the current study disagreed with the results of a Mirza (2013) study in Saudi society, which indicates to the presence of weaknesses limit the effectiveness of early intervention services Such as the lack of clear national policies as well as the limited of scientific research to keep up with global research and the difficulty of determining the size of disability in early childhood under six years, and it differs as well as with the results of El-Al-Sherbini and Sayed (2013) study which indicated that (50.25) of the sons of Egyptian society did not enroll their children with Intellectual disabilities early intervention programs, and consistent with the results of a study (Ghulam \& Kady, 2015).

The third question, the results showed that there were no statistical differences between the responses of workers in intellectually disability centers in Ma'an governorate about the axis of the importance of early intervention services for children with Intellectual disabilities due to the variables of (Gender-Years of ExperienceQualifications-Specialization-Place of Center).

Interpretation of the lack of influence of the gender maybe indicate to no difference between males and females with regard to the importance of early intervention services, but with regard to the experience years, the workers in these centers in addition to what they have of prior knowledge about the early intervention they are involved in training courses in this area so there is no impact to the variable for years' experience, respect to qualification variable, the qualifications is not less than a high school so it is suitable qualifications, and the researcher has noticed through direct communication with the employees in these centers they are characterized by knowledge and broad view in the field of disability, regardless of qualification, Most of them have pointed out that the great desire to service this category are motivated to get knowledge through different means of communication such as the internet, books, pamphlets, television and communicate with specialists, as well as with respect to variable specialization the early intervention is referred to various disciplines, in addition to that most workers specialization in the centers is special education, the same applies for years of experience even the place variable was not statistically significant because the means of access to knowledge is available in the city and village alike, especially with regard with the internet, the previous results came consistent in some respects with the study results of (Al-Wohaib, 2013).

Finally, it has revealed the results by analysis of the fourth question about the lack of statistically significant differences at $(\alpha \leq .05)$ among workers responses in those centers with respect to variables of (Gender-years of experience-qualification-specialization), while there is exist statistically significant differences at the level ( $\alpha$ $\leq .05)$.

This result was attributed to the gender variable, where it is not related with it, everyone expressed about his or her opinion far from being a male or a female, but the years of experience, qualifications and specialization so the agreement between the respondents responses was not affected by these variables they are studying theoretical and applied subjects in the field of special education, such as outreach, guidance and the programs building and other areas of special education in the field of disability, as they all receive continuous training courses to provide the necessary services for the intellectual disabled, and that these centers provide developed means and mechanisms for the training of cadres working in it.

This result is attributed-generally-that Jordan has witnessed great interest in the prevention of disability, the attention is increasing to the health and medical aspects of care through official institutions such as the Ministry of Health, civilian and military medical institutions and various of hospitals and health centers by work and coordinate with each other through the development of comprehensive and public policy for the advancement of physical and psychological health of the individual and to spread the awareness of the health and social, support the continuous prevention programs such as vaccination of children against communicable diseases, the prevention of accidents, work-related injuries, traffic accidents and home accidents, focus on the causes of disability, study and analysis of the factors that causative through early detection, as well as on the role of prominent media through various means such as television, radio, press and specialized magazines, And the pursuit to put system of (detection and early diagnosis), counseling and guidance family, genetic and psychological guidance and represented through centers and institutions specialize in such of these programs (Al-Khatib \& Al-Hadeedy, 2016; Al-Roussan, 2013), also Jordan has witnessed in this area convene many conferences, seminars and training courses, as well as the academic programs have been appeared on the level of bachelor's, master's and doctoral with regard to disability.

And it varies with the study of (Al-Wohaib, 2013) with respect to a service year's variable and for the benefit of those with more than five years of service. It differed as well as with some of the results of the study and the (Al-Qarni, 2007) was impact there of gender (males are more effective than female), as well as educational qualification was for the benefit of Graduate Studies, also it agreed with some aspects of study of (Neitzel, 2004), 
While there was a statistically significant differences regarding to the place of center and it can be explained as a expected result because the centers in the city receive support and attention to the larger as they the center and this in turn attracts specialists, while in the villages the spatial dimension may sometimes prevents the availability of some services, so it is making the cities better than the villages with respect to place variable.

\section{Recommendations}

On the light of the generated outputs herein, the researcher presents the following recommendations and suggestions:

The Bachelor degree subjects must include applications in the early intervention and rehabilitating graduates of intellectual disability track to work within early intervention programs directed to I. D. children. Moreover, increasing the students number who are enrolled in specialties that serve the early intervention program, consolidate specialists efforts and initiate team work consisting of various specialties and coordinating the services and efforts.

Conduct similar studies on centers that provide the services for other categories of persons with disabilities in different areas in Jordan. Conducting new that tackles the current study variables, either separately or accompanied with other variables, to achieve more assurance as to the current study outputs. Also subjecting workers in those centers more internal and external courses about taking care of individuals with disabilities, provide more attention and support for the centers that taking care for the disabled in the distant area .

\section{References}

Abaid, M. (2012). Evaluation of efficiency level for governmental and special mental retardation centers at Amman governorate. Islamic University magazine for educational and psychological studies, 20(2), 95-128. Retrieved from http://www.iugaza.edu.ps/ar/ periodical

Abid, M. (2005). Obstacles of services that present to the intellectual disabled in the northern Gaza Strip. Retrieved from http://www.pmrs.ps/userfiles/file/Research3.doc

Al-Hazmi, M. (2007). Prevention of disability: Stages of pre-family. Arab Bureau of Education for the Gulf States, Riyadh.

Al-Khatib, J. M., \& Al-Hadidi, M. (2016). Early Intervention (9th ed.). Dar Alfikr, Amman.

Al-Naimi, F. A. (2008). Evaluation the early intervention programs that provided for the intellectual disabled in the United Arab Emirates from the perspective of mothers and teachers (Unpublished Master thesis, Amman Arab University for Higher Studies).

Al-Naqbi, F. (2015). The importance of early intervention and (the treatment and rehabilitation programs). Worksheet. International Conference for Special Education. Sharjah-United Arab Emirates, 259-267.

Al-Qarni, S. (2007). The point of view of workers in the effectiveness of early intervention programs provided for the hearing impaired for government and private institutions in Jeddah from the perspective of workers (Un-published Master thesis, University of Yarmouk. Jordan).

Al-Rousan, F. (2010). Introduction to mental retardation (4th ed.). Jordan University.

Al-Rousan, F. (2013). Issues and problems in Special Education. Dar Alfikr. Amman.

Al-Sherbini, M., \& Sayed, R. (2013). Challenges that hinder the application of early intervention for people with Intellectual disabilities Statistics conceived with the proposal from the perspective of the general practice of social service to meet these challenges (a comparative study between the Omani society and the Egyptian society). Worksheet. Forum XIII Gulf Disability Society. Under the slogan of (Early Intervention-investment for the future). Manama. Bahrain.

Al-Wohaib, A. (2013). Early intervention services for deaf children and hearing impaired. Worksheet. Forum XIII-Gulf Disability Society. Under the slogan of (Early intervention-an investment for the future). Manama. Bahrain.

Al-Zeriqat, I. (2009). Early intervention models and procedures (1st ed.). Dar march, Amman.

Armstrong, K. H. et al. (2014). Evidence-Based Interventions for Children with Challenging Behavior. Springer Science+Business Media, New York.

Department of Statistics. (2016). Jordan. Report the main results of the General Census of Population and Housing 2015. Retrieved from http://census.dos.gov.jo/wp-content/uploads/sites/2/2016/02/Census_results_ 2016.pdf 
Ghulam, E. \& Kadi, N. (2015). The level of services provided by Special educational institutions in Tripoli-Libya. The importance of early intervention and (treatment and rehabilitation programs). Worksheet. International Conference for Special Education. Emirates-Sharjah (pp. 103-110).

Hebbeler, K., Spiker, D., Bailey, D., Scarborough, A., Mallik, S., Simeonsson, R., \& Singer, M. (2007). Early intervention for infants and toddlers with disabilities and their families: participants, services, and outcomes. Final report of the National Early Intervention Longitudinal Study (NEILS).

Landa, R. J., Holman, K. C., O'Neill, A. H., \& Stuart, E. A. (2010). Intervention targeting development of socially synchronous engagement in toddlers with autism spectrum disorder: A randomized controlled trial. Journal of Child Psychology and Psychiatry, 52(1), 13-21.

Mirza, H. (2013). Early intervention system: an analytical look at the reality and future ambition for early intervention services in Kingdom of Saudi Arabia as a model. Worksheet. Forum XIII Gulf Disability Society. Under the slogan of (Early intervention-an investment for the future). Manama. Bahrain.

Osofsky, J. D., \& Lieberman, A. F. (2011). A call for integrating a mental health perspective into systems of care for abused and neglected infants and young children. American Psychologist, 66(2), 120-128. http://dx.doi.org/10.1037/a0021630

Rosenberg, S., Zhang, D., \& Robinson, C. (2008). Prevalence of developmental delays and participation in early intervention services for young children. Pediatrics, 121(6) e1503-e1509. http://dx.doi.org/10.1542/peds.2007-1680

Yeyha, Kh. (2006). Educational programs for special needs individuals. Masserah house, Amman.

\section{Copyrights}

Copyright for this article is retained by the author(s), with first publication rights granted to the journal.

This is an open-access article distributed under the terms and conditions of the Creative Commons Attribution license (http://creativecommons.org/licenses/by/4.0/). 